\title{
Identificação de elementos objetivos e subjetivos no comportamento do consumidor como suporte ao desenvolvimento de produtos: um estudo na atividade turística
}

\author{
Identification of objective and subjective elements on consumer behavior as support to the \\ products development: a study at tourist activity
}

\author{
Mauro Caetano (CAETANO, M.), Leonardo Francisco Figueiredo Neto (FIGUEIREDO NETO, \\ L. F.), Carlos Alberto Xavier do Nascimento (NASCIMENTO, C. A. X. do) e Milton Augusto \\ Pasquoto Mariani (MARIANI, M. A. P.)
}

\begin{abstract}
RESUMO - Serviços relacionados à alimentação se constituem na maior contribuição dos gastos realizados pelos turistas durante suas viagens. Dessa forma, torna-se importante identificar os fatores que interferem no seu comportamento alimentar, tema esse pouco explorado pela literatura da área. Esse trabalho busca apresentar alguns elementos objetivos e subjetivos, tratados aqui como utilitarismo e hedonismo, respectivamente, que são considerados pelos consumidores nas suas escolhas por produtos alimentícios quando visitam um destino turístico. A partir de uma pesquisa exploratória e uma survey junto a turistas durante sua visita a um destino turístico, identificou-se que as orientações hedônicas no consumo de alimentos, mais evidentes entre turistas do sexo feminino, interferem significativamente no comportamento dos consumidores. A principal contribuição do trabalho está na análise desses elementos e sua contribuição para o desenvolvimento de novos produtos turísticos.
\end{abstract}

Palavras-chave: Comportamento do Consumidor; Consumo alimentar; Turismo.

\begin{abstract}
Food services can be considered the largest contribution of the expenses accomplished by tourists during their trips. This way, it is important to identify the factors which interfere in the food consumer behavior, issue a bit explored by the area literature. This study seeks to present some objective and subjective elements, called here as utilitarism and hedonism, which are consider by consumers during their choices for food products when they are visiting a tourist destiny. By an exploratory research and a survey with the tourists during their touristic destination visiting, it was identified that the hedonist orientation for food consumption, more evident among female tourists, has a great impact on the consumer behavior. The main contribution of this study is in the analysis of these elements and its contribution to the development of new tourist products.
\end{abstract}

Key words: Consumer behavior; Food consumption; Tourism.

* Mauro Caetano. Graduação em Turismo com ênfase em Planejamento Turístico (UFPR). Mestrado em Agronegócios (UFMS/UnB/UFG). Doutorado em Engenharia de Produção (USP). Professor da Faculdade de Administração, Ciências Contábeis e Economia (FACE) da Universidade Federal de Goiás (UFG). Endereço: Campus Samambaia (UFG). Caixa postal: 131, CEP: 74001-970 - Goiânia - Goiás (Brasil). Telefone: (62) 35211390. E-mail: maurocaetano1912@gmail.com.

Leonardo Francisco Figueiredo Neto. Graduação em Agronomia pela Universidade Federal do Espírito Santo (UFES). Mestrado em Ciências (Economia Aplicada) pela USP. Doutor em Engenharia de Produção (USP). Professor do Mestrado em Administração da Universidade Federal do Mato Grosso do Sul (UFMS). Endereço: Avenida Senador Filinto Muller, 1550 (Vila Ipiranga - Unidade 10). CEP: 79070-900 - Campo Grande - Mato Grosso do Sul (Brasil). Telefone: (67) 3345-3573. Fax: (67) 3345-6621. E-mail: lffneto@nin.ufms.br.

Carlos Alberto Xavier do Nascimento. Graduação em Administração de Empresas com ênfase em Análise de Sistemas (Faculdades Integradas Rui Barbosa). Mestrado em Agronegócios (UFMS/UnB/UFG). Coordenador do Curso de Administração de Empresas na Faculdade de Administração e Negócios (REGES - Rede Gonzaga de Ensino Superior) de Ribeirão Preto/SP. Endereço: Rua Tereza Cristina, 2521, apto 22, Jardim Paulistano. CEP 14090-320 - Ribeirão Preto - São Paulo (Brasil). Fone: (16) 2138-1868. E-mail: cnascimento3@ yahoo.com.br.

Milton Augusto Pasquotto Mariani. Graduação em Geografia pela Universidade Estadual Paulista Júlio de Mesquita Filho. Mestrado em História Social pela Pontifícia Universidade Católica de São Paulo. Doutorado em Geografia (Geografia Humana) pela USP. Professor do Mestrado em Administração da UFMS. Endereço: Avenida Senador Filinto Muller, 1550 - Vila Ipiranga - Unidade 10. CEP: 79070-900 - Campo Grande - Mato Grosso do Sul (Brasil). Telefone: (67) 3345-3573. Fax: (67) 33456621. E-mail: miltmari@terra.com.br. 


\section{INTRODUÇÃO}

O desenvolvimento de novos produtos e serviços, bem como o estabelecimento de condições para a sua aceitação no mercado, está estreitamente relacionado ao comportamento do consumidor e as demandas de mercado e, por isso, a identificação de mecanismos para se ouvir e interpretar a "voz do consumidor" caracteriza-se como sendo uma das atividades chaves quando se trata do desenvolvimento de produtos turísticos (CLARK; WEELWRIGHT, 1993). Entender os motivos e fatores que orientam as escolhas dos consumidores, a partir das suas necessidades, sejam elas objetivas ou subjetivas, pode estar na fronteira entre o sucesso e insucesso dos negócios, sobretudo em um setor como o do Turismo, de importância econômica estratégica para os países, em que essas motivações estão em constante relacionamento.

As atividades relacionadas ao planejamento de produtos turísticos, similarmente a produtos manufaturados, conforme proposto por Rozenfeld et al. (2006), devem ser orientadas no sentido de se atender às necessidades dos consumidores que, aqui caracterizados como turistas, determinam quais elementos objetivos ou subjetivos determinam suas escolhas por produtos específicos. No caso da atividade turística, tais produtos referem-se aos meios de hospedagem ou transporte, que lhes gere o melhor conforto e segurança possível e, principalmente, o alimento que melhor atenda as suas necessidades durante a visita a um destino.

Tais necessidades dos consumidores podem ser caracterizadas, de acordo com Babin, Darden e Griffin (1994), como utilitárias, relacionadas às suas questões fisiológicas, ou hedônicas, relacionadas às sensações de prazer durante uma viagem, diferenças essas que norteiam a realização desse trabalho.

Apesar do impacto que os serviços de alimentação representam para a economia do Turismo, pois, de acordo com Quan e Wang (2004), mais de 25\% dos gastos dos turistas são realizados em serviços e produtos relacionados à alimentação, nota-se que o tema não tem recebido a devida atenção da literatura nos últimos anos. Esse fato, através do entendimento das motivações turísticas em relação ao consumo de alimentos, impacta diretamente nas decisões de planejamento desse tipo de produto turístico (HJALAGER; CORIGLIANO, 2000; REYNOLDS, 1994). 
Durante o processo de aquisição de um produto ou serviço alimentício, de acordo com Babin et al. (2005), o consumidor busca equalizar os custos e benefícios desse processo e determina o valor atribuído a essa aquisição, o que pode ser avaliado em termos utilitários ou hedônicos. A identificação junto ao mercado consumidor dos fatores que implicam no planejamento de um produto turístico, como o comportamento dos turistas em relação ao alimento, constitui-se em um elemento fundamental para a tomada de decisão por parte dos desenvolvedores de produtos turísticos.

Batra (1991) apresenta que a identificação dos componentes hedônicos e utilitários de consumo é fundamental para o desenvolvimento de produtos, pois, a partir das atitudes dos consumidores, podem ser levantados os atributos que interferem no seu comportamento e, dessa forma, realizar distinções entre categorias de produtos e seus respectivos consumidores.

Sendo assim, o objetivo do presente trabalho se constitui na apresentação de alguns elementos objetivos e subjetivos que são considerados pelos consumidores nas suas escolhas por produtos alimentícios durante suas viagens, o que pode contribuir não apenas para a o desenvolvimento de novos produtos turísticos, mas, também para a orientação na segmentação de mercado na atividade turística.

\section{MÉTODO}

As atividades realizadas nesse estudo o classificam, de acordo com Malhotra (2006), como uma pesquisa exploratória, pois foram realizadas pesquisas bibliográficas sobre os temas em análise, de modo a melhor compreender as temáticas envolvidas no estudo e identificar um modelo de classificação do comportamento de compra, apresentado por Babin, Darden e Griffin (1994), bem como a realização de uma survey com o propósito de se identificar o comportamento do turista em relação às suas motivações para a alimentação no destino turístico.

Os entrevistados, classificados como turistas pela Organização Mundial do Turismo - OMT (1994), foram questionados em relação às suas motivações para a aquisição de produtos e serviços relacionados à alimentação durante suas estadas no destino, como, por exemplo, a questão norteadora desse trabalho: “O que lhe motivou a 
escolher esse(s) produto(s)? / What is the reason that you have chosen this(ese) product(s)?". Por esperar que a resposta do entrevistado se enquadrasse entre os itens "utilitário" ou "hedônico", deixar a questão aberta permitiu uma melhor compreensão do comportamento dos consumidores.

As entrevistas foram realizadas inicialmente de modo qualitativo, com questões abertas aplicadas a doze turistas, que possibilitou o agrupamento de determinadas opções e disponibilizá-las em questões fechadas, aplicadas em um segundo momento junto a uma amostra aleatória estratificada, utilizando questionário auto-administrado com questões abertas e fechadas identificando características sócio-demográficas e comportamentais dos turistas. Foi utilizada uma amostra de 93 pessoas, entrevistadas em 17 hotéis de diferentes categorias da cidade de Campo Grande, o que confere ao estudo um grau de confiabilidade de $90 \%$ e margem de erro de 7,8\% (MUROLO, 1997).

De posse dos questionários, as respostas dos entrevistados, no que se refere às motivações de compra, foram então interpretadas e comparadas com a escala de comportamento apresentada por Babin, Darden e Griffin (1994), sendo utilizado o método comparativo proposto por Glaser e Strauss (1967) que, apesar de possibilitar a generalização de dados em uma pesquisa qualitativa, também gera a possibilidade de se desenvolver teorias fundamentadas em dados empíricos. Essa comparação foi realizada a partir de uma análise teórica de caráter indutivo baseada em revisão de literatura (KARLSSON, 2009).

$\mathrm{Na}$ sequiência, foi realizada uma análise estatística que norteou as principais considerações do trabalho, em que se fez o uso do teste qui-quadrado $(\chi 2)$ e o teste de média com a pretensão de se conferir um maior rigor estatístico ao estudo (SIEGEL, 1977).

\section{CARACTERIZAÇÃO GERAL DO TURISMO}

Compreender o turismo com objetividade e exatidão não se constitui em uma tarefa simples do ponto de vista da ciência, pois, conforme apontado por Dencker (2001), ele se constitui a partir de um conjunto de atividades de natureza heterogênea que impedem a solidificação de uma ciência autônoma e de técnicas independentes, 
caracterizado pela ausência de um ordenamento disciplinado e rígido de práticas e conceitos.

Tem-se que as viagens realizadas com o propósito turístico se caracterizam como uma espécie de fuga do cotidiano em busca de experiências diferentes e exercício dos hábitos presentes em uma sociedade de consumo (KRIPPENDORF, 1989), ou seja, diferentes implicações sobre o fenômeno do Turismo podem ser realizadas a partir da Sociologia e Marketing, em relação à mobilidade e comportamento do consumidor, da Economia, em relação aos impactos ocasionados pelo deslocamento de divisas, entre tantas outras ciências que se complementam na configuração do Turismo.

As origens da atividade são apontadas por Urry (1999) a partir do chamado grand tour, firmemente estruturado no final do século XVII, em que jovens aristocratas ingleses realizavam viagens de estudo às principais cidades européias da época. $\mathrm{Na}$ ocasião, o Turismo já despontava como uma ciência que, para ser compreendida, necessitava de reflexões acerca de três princípios básicos: o homem, o espaço e o tempo. As relações entre esses três fatores fundamentam a atividade na sua principal essência como um fenômeno humano (ANDRADE, 1998).

A apresentação de dados estatísticos sobre a atividade não se torna necessária nesse trabalho em função da sua rápida desatualização frente aos indicadores internacionais, entretanto, cabe ressaltar que a atividade possui uma importância significativa na economia brasileira, tendo gerado em 2007, de acordo com o Ministério do Turismo (2009), um valor equivalente a R $\$ 39$ bilhões em receitas, ou 2,6\% do PIB brasileiro. Já os serviços de alimentação no Turismo representaram cerca de $40 \%$ desse valor, ou o equivalente a cerca de $\mathrm{R} \$ 15$ bilhões, o maior responsável pelo impacto econômico do Turismo (IBGE, 2009). Esses dados ressaltam a dimensão que os serviços de alimentação possuem na atividade turística, o que reforça a necessidade de se considerar as motivações dos turistas em relação a esses serviços.

\subsection{MOTIVAÇÕES DOS TURISTAS}

Diferentes modelos motivacionais podem ser utilizados para se compreender as motivações turísticas, como o apresentado por Deci e Ryan (1985), que tratam do alcance de determinados objetivos relacionados à auto-estima. De modo mais enfático, 
Hochschild (1983) trata da comercialização dos sentimentos humanos, entretanto, o modelo apresentado por Maslow (1953), que considera a hierarquia das necessidades humanas, talvez seja um dos mais apropriados para se analisar o comportamento do turista. De acordo com o autor, as pessoas deveriam procurar satisfazer uma necessidade, situada na pirâmide de Maslow, somente quando uma necessidade anterior já estivesse sido satisfeita, ou seja, antes de se empenharem em atividades como a prática de lazer com a família, por exemplo, o indivíduo deveria atender as suas necessidades por segurança e, principalmente, fisiológicas por alimentos (MASLOW, 1953).

No que se refere às escolhas das pessoas por um determinado alimento, essa decisão está relacionada a vários fatores que determinam o seu comportamento enquanto consumidores. Gains (1999) distribui alguns desses fatores em três diferentes grupos, conforme a figura 1.

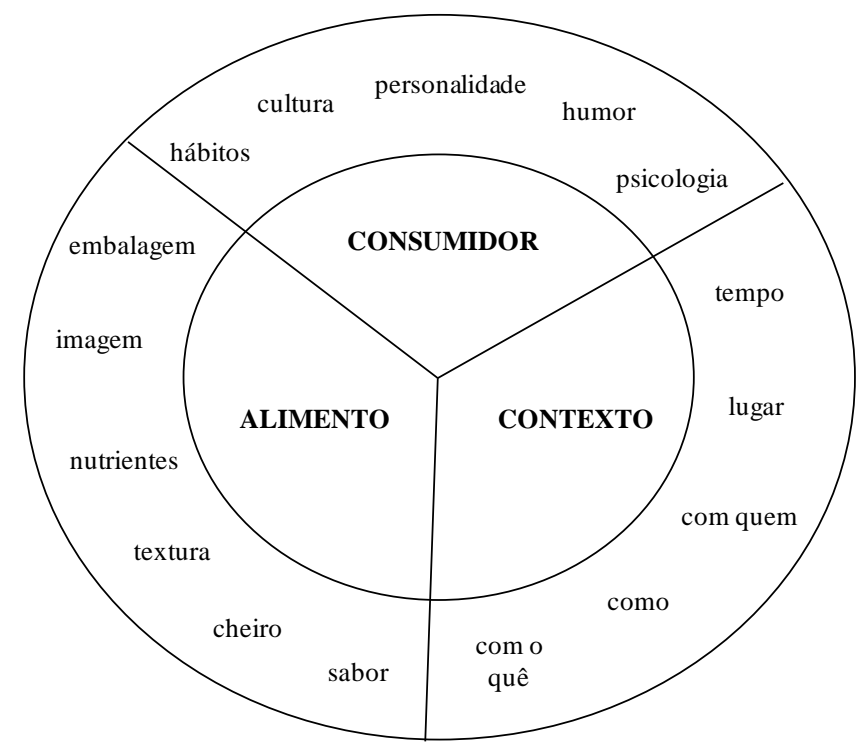

FIGURA 1: ITENS RELACIONADOS À ESCOLHA POR DETERMINADO ALIMENTO. FONTE: GAINS, 1999.

Em sua análise, Gains (1999) utiliza o Método Repertório de Grade (RGM) para formular, testar, verificar e atualizar hipóteses relacionadas a esses três diferentes itens: consumidor, alimento e o contexto nas preferências alimentares dos consumidores. $\mathrm{O}$ autor argumenta que, a partir de fatores como o tempo, lugar, com quem, como e com o quê se escolhe determinado produto, diferentes resultados podem ser observados com relação à decisão de compra pelo consumidor. 
Nesse sentido, o presente estudo possui como foco principal esse último fator, o contexto, pois, dada a característica da atividade turística, em que o turista escolhe seu alimento em um contexto diferente daquele que ele vive diariamente, as decisões de escolha alimentar possuem peculiaridades que se apresentam somente diante de determinadas experiências que os turistas vivem durante sua viagem (QUAN; WANG, 2004).

\subsection{VALORES ATRIBUÍDOS AOS ALIMENTOS PELO TURISTA}

Antes de optar pelo consumo de determinado produto alimentício, o consumidor lhe atribui valores com base em atributos intrínsecos, como suas características organolépticas e funcionais, e atributos extrínsecos, como a representação simbólica desse alimento e seus fatores lúdicos (BECKER, 2000). Esses atributos embasam a percepção de qualidade que, por conseguinte, oferece subsídios para a percepção de valor do alimento.

Por alimento utilitário ou funcional entende-se qualquer alimento, em forma natural ou processada, que, além dos seus componentes nutritivos, contém componentes adicionais que favorecem a saúde, a capacidade física e o estado mental de uma pessoa. Também podem ser considerados funcionais aqueles alimentos que são modificados, fortificados ou enriquecidos, especialmente com adição de vitaminas e minerais, com vistas a aumentar seu valor nutricional e atender as necessidades de determinada população (MORALES, 2002).

Já a escolha alimentar com base no hedonismo está fortemente associada à sensação de prazer vivida pelo ser humano. Segundo o filósofo grego Aristóteles (384 322 a.C.), citado por Triska (2003), a vida e o prazer não são separáveis, pois sem o comportamento não há prazer, e o prazer aperfeiçoa o comportamento, o que corrobora para as necessidades dos consumidores no exercício da atividade turística.

Originado do grego hedone, que significa prazer, o hedonismo se constitui em uma doutrina moral que considera o prazer como a finalidade da vida (LAROUSSE CULTURAL, 1992). Dessa forma, o comportamento do consumidor no Turismo possui uma estreita relação com a sua sensação de prazer no consumo de um produto alimentício. 


\subsection{CLASSIFICAÇÃO DO COMPORTAMENTO DO TURISTA}

Para que fosse possível a classificação do comportamento dos entrevistados nesse trabalho em orientações utilitárias ou hedônicas, foram adotadas como modelo as variáveis da escala de comportamento de compra apresentada por Babin, Darden e Griffin (1994). Os autores desenvolveram essa escala a partir da realização de pesquisas na literatura sobre o tema, seguidas de dois grupos focais. Quando questionados sobre os valores pessoais que os entrevistados atribuíam ao processo de compra, foram obtidas 71 respostas que foram categoricamente classificadas pelos autores em uma escala utilitária e outra hedônica. Após essa análise, foi realizada uma pesquisa com 440 moradores de comunidades norte-americanas. Com a utilização de análise de fator, os autores elencaram as 15 principais variáveis que interferem no processo de compra por parte dos consumidores, que são retratadas a partir das frases apresentadas na tabela 1 .

TABELA 1 - FRASES DOS CONSUMIDORES PARA AS VARIÁVEIS EM RELAÇÃO À ESCALA DE ORIENTAÇÃO

\begin{tabular}{c|c}
\hline ESCALA & VARIÁVEIS \\
\hline \multirow{4}{*}{ UTILITÁRIA } & Eu consegui obter exatamente o queria nessa atividade. \\
\cline { 2 - 2 } & Eu não consegui comprar o que eu realmente procurava. \\
\cline { 2 - 2 } & Eu me senti desapontado, pois tive que ir a outra loja completar minhas compras. \\
\cline { 2 - 2 } & Foi uma boa atividade, pois pude encontrar o que eu precisava rapidamente. \\
\cline { 2 - 2 } & Eu continuei a fazer compras, não porque tinha que fazer, mas por que eu queria. \\
\cline { 2 - 2 } & Esta atividade representou um sentimento de fuga. \\
\cline { 2 - 2 } & Comparado com outras coisas que eu poderia ter feito, o tempo gasto durante as \\
& compras foi realmente muito prazeroso. \\
\cline { 2 - 2 } & Eu me diverti estando envolvido com novos produtos. \\
\cline { 2 - 2 } & Eu me diverti nessa atividade por si só, e não apenas pelos itens que pude encontrar. \\
\cline { 2 - 2 } & Foi um bom período por que eu pude agir no impulso do momento. \\
\cline { 2 - 2 } & Durante essa atividade eu senti a excitação da caça. \\
\cline { 2 - 2 } & Durante essa atividade eu pude esquecer meus problemas. \\
\cline { 2 - 2 } & Durante essa atividade eu senti uma sensação de aventura. \\
\cline { 2 - 2 } &
\end{tabular}

FONTE: BABIN, DARDEN E GRIFFIN (1994).

De acordo com a tabela 1, pode-se observar que, nas atividades relacionadas ao utilitarismo, o caráter da objetividade na decisão, como a obtenção do que se planejava ou, por outro lado, da sua não obtenção, deixam claro quais as necessidades utilitárias dos turistas poderiam ser sanadas com o comportamento orientado por essa escala. Um 
exemplo disso seria a satisfação física obtida com o alimento, refletida através do valor fisiológico da alimentação no atendimento das necessidades por nutrientes.

Já na escala hedônica, em que se podem notar claramente elementos da busca pelo prazer ou diversão, o turista também leva em consideração esses elementos na aquisição de um produto alimentício. Trata-se de um valor mais subjetivo e pessoal do que aquele atribuído ao utilitário, pois está associado ao prazer e seus sentimentos lúdicos, elementos marcantes da atividade turística.

Cabe aqui ressaltar que a escala apresentada na tabela 1 foi utilizada como referencial na análise dos resultados desse trabalho de modo aproximado, ou seja, as respostas dos entrevistados durante essa pesquisa foram comparadas qualitativamente com tais variáveis e adotadas aquelas que mais se aproximaram da escala apresentada (GLASER; STRAUSS, 1967).

\section{ANÁLISE DOS RESULTADOS E DISCUSSÕES}

Do total de entrevistados nesse trabalho, $74 \%$ corresponderam ao sexo masculino e $26 \%$ ao sexo feminino. A faixa etária dos entrevistados esteve entre 17 e os 61 anos. Sua renda mensal apresentou-se entre $\mathrm{R} \$ 350,00$ e $\mathrm{R} \$ 18$ mil. Uma quantidade de $68 \%$ dos entrevistados já havia estado antes em Campo Grande, sendo que 32\% deles se encontravam pela primeira vez na cidade, o que demonstrou um significativo percentual de novos consumidores. Tratava-se de pessoas que estavam visitando a cidade a negócios (60\%), para participar de eventos (16\%), a lazer (11\%), a estudos (4\%), para visitar parentes e amigos (4\%), entre outros. A procedência desses turistas era de diversas unidades da Federação, sendo que São Paulo conferiu um maior número de participantes nesse trabalho (29\%), seguido pelos moradores do próprio Estado de Mato Grosso do Sul (24\%), Paraná (16\%), Rio Grande do Sul (5\%), Mato Grosso (5\%), Santa Catarina (4\%), entre outras, além de turistas do exterior (2\%).

Do total de entrevistados nessa pesquisa, foi identificado no estudo que $70 \%$ dos turistas apresentaram características predominantemente utilitárias, sendo que os demais $30 \%$ apresentaram características hedônicas de consumo, baseado no modelo proposto por Babin, Darden e Griffin (1994), conforme apresentado na figura 2. 


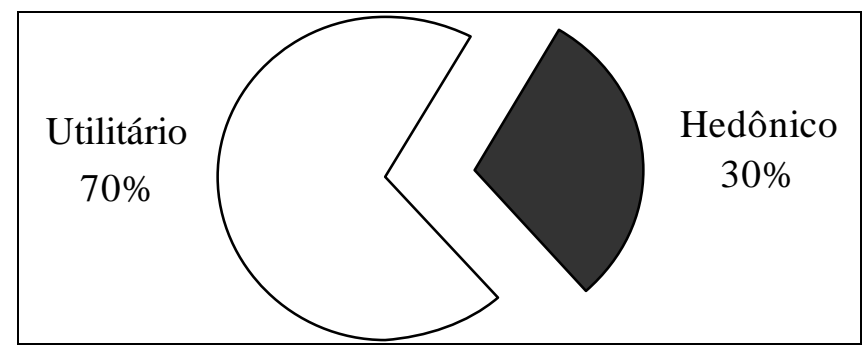

FIGURA 2 - CARACTERIZAÇÃO DO COMPORTAMENTO ALIMENTAR DOS TURISTAS FONTE: DADOS DA PESQUISA.

Pelas definições apresentadas por Maslow (1953), referentes às necessidades básicas do ser humano, constituídas em necessidades fisiológicas, pode-se notar que o comportamento do turista baseado no utilitarismo se apresentou como predominante devido às funções nutritivas do alimento e sua importância para a integridade física. Entretanto, nota-se que, de acordo com a pesquisa, um percentual significativo de turistas teve o seu consumo orientado pelo comportamento hedônico. Foram motivações baseadas em características emocionais dos turistas, ou seja, os aspectos emocionais no consumo alimentar transpuseram os aspectos racionais de manutenção do corpo humano.

Questionados sobre os motivos que os levaram a escolher determinados pratos, os turistas responderam que a curiosidade por novos pratos e pela tradição, além do desejo de conhecer e consumir um prato típico estavam entre os principais motivos de suas escolhas, o que justifica o comportamento hedônico. Já aqueles que com um comportamento voltado para o utilitarismo, apresentaram como principais motivações na escolha de determinado produto a fome, o preço e a qualidade dos produtos.

De acordo com gênero dos turistas, nota-se que a predominância para o comportamento hedônico no consumo de alimentos foi identificada entre as mulheres, cerca de $70 \%$ dos turistas hedônicos, sendo que entre os turistas com comportamento utilitário de alimentação, cerca de $60 \%$ correspondia aos homens. O gráfico 1 apresenta essa distribuição. 


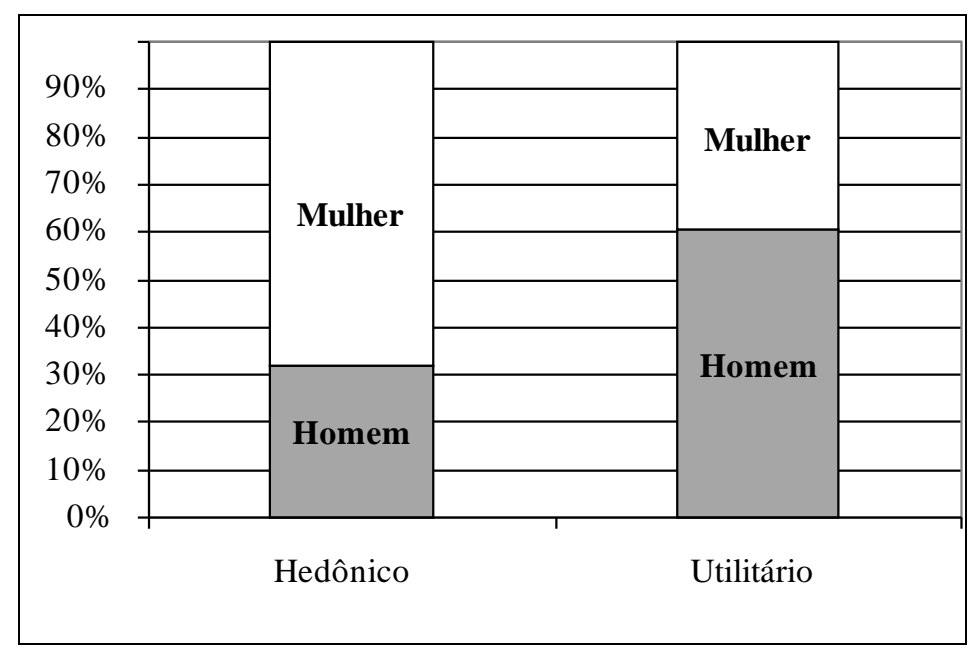

GRÁFICO 1 - CARACTERIZAÇÃO DO COMPORTAMENTO A PARTIR DO GÊNERO DOS TURISTAS

FONTE: DADOS DA PESQUISA

Quando analisado o local onde os turistas realizaram suas refeições, foi constatado que aqueles turistas que eram orientados pelo comportamento hedônico faziam suas refeições principalmente na Feira Central (40\%), que se tratava de um local no Centro da cidade onde eram comercializados produtos típicos da região, seguido pelos restaurantes típicos (30\%) e pelos restaurantes tradicionais (10\%), empatados com o shopping da cidade e lanchonetes com também $10 \%$ das preferências.

Já em relação aos turistas orientados pelo comportamento utilitário no consumo de alimentos, foi constatado que a maioria realizou suas refeições na casa de amigos ( $22 \%)$ ou no próprio hotel (22\%), sendo que os demais realizaram suas refeições em restaurantes, no shopping ou em lanchonetes (17\% para cada um) e apenas $5 \%$ realizaram suas refeições em restaurantes típicos.

Pode-se notar que, a partir da proximidade dos índices, não houve uma preferência relevante por local de consumo do alimento pelos turistas orientado pelo comportamento utilitário, sendo que o local que melhor lhes conviesse, a partir das suas necessidades de tempo e dinheiro, de acordo com a pesquisa, foi o escolhido.

Em relação ao motivo de viagem, os turistas com maiores propensões ao comportamento hedônico foram aqueles que estavam participando de eventos, sendo que $46 \%$ deles estavam propensos a esse comportamento, seguidos dos turistas que visitavam a cidade a negócios (25\%) e pelos turistas de lazer (20\%). Já em relação ao comportamento utilitário, as motivações apresentavam sentido oposto ao 
comportamento hedônico, sendo que os turistas que visitavam a cidade a lazer foram, na sua maioria, utilitários (80\%), seguidos dos que visitavam a cidade a negócios (75\%) e pelos participantes em eventos na cidade (53\%).

Entre os principais produtos consumidos pelos turistas, foi identificado que $14 \%$ dos produtos consumidos foram peixes, seguidos de $13 \%$ referentes à carne assada (churrasco), $9 \%$ sendo composto por outros tipos de carnes com diferentes preparos, $4 \%$ de lanches rápidos e 3\% de sobá, um produto típico da região feito à base de macarrão.

Os resultados de testes estatísticos, apresentados na tabela 2, são apresentados a partir dos testes qui-quadrado ( $\chi 2)$ para as variáveis "Procedência", "Gênero", "Freqüência de visita", "Motivo da viagem" e "Forma de viagem". O teste $\chi^{2}$ de uma amostra, de acordo com Siegel (1977), consiste na aplicação de uma fórmula matemática que busca comprovar se existe diferença significativa entre o número observado de indivíduos, ou de respostas, em determinada categoria, e o respectivo número esperado, baseado na hipótese de nulidade.

Na tabela 2 também são apresentados testes de média para se verificar a relação existente entre o comportamento alimentar e a faixa etária dos turistas, renda mensal e os dias de permanência na cidade. A significância entre as categorias analisadas existe quando se obtém um p-valor $\leq 0,05$ (SIEGEL, 1977).

TABELA 2 - RESUMO DOS TESTES DE SIGNIFICÂNCIA

\begin{tabular}{c|c|c|c|c}
\hline VARIÁVEIS & $\chi^{2}$ & g. l. & p-valor & $\begin{array}{c}\text { Há diferença } \\
\text { significativa? }\end{array}$ \\
\hline Procedência & 1,628 & 3 & 0,653 & NÃO \\
\hline Gênero & 6,083 & 1 & 0,014 & SIM \\
\hline Freqüência de visita & 0,000 & 1 & 0,988 & NÃO \\
\hline Motivo da viagem & 2,036 & 1 & 0,154 & NÃO \\
\hline Forma de viagem & 3,095 & 1 & 0,079 & NÃO \\
\hline Faixa etária & - & - & 0,486 & NÃO \\
\hline Renda mensal & - & - & 0,392 & NÃO \\
\hline Permanência no destino & - & - & 0,648 & NÃO \\
\hline
\end{tabular}

FONTE: DADOS DA PESQUISA. 
Como pode ser constatado pela tabela 2, a maioria das variáveis estudadas, de acordo com a análise estatística, não interferiu no comportamento alimentar dos turistas, entretanto, a variável gênero interferiu de forma significativa, pois apresentou um pvalor $<0,05$. Esse dado demonstra a possibilidade de segmentação do mercado turístico com relação ao comportamento alimentar de homens e mulheres. Dessa forma, pode ser dada uma maior ênfase no marketing de produtos turísticos aos fatores objetivos do público masculino, bem como aos fatores subjetivos mais dirigidos ao público feminino. Com isso, os esforços aplicados tanto no desenvolvimento quanto na divulgação de novos produtos turísticos poderiam ser otimizados.

Os dados apresentados demonstram que os fatores como o gênero do turista, local de consumo de alimento, motivo da viagem e produtos consumidos possuem uma relação significativa com o comportamento alimentar dos turistas.

Apesar de o presente trabalho ter sido bi-polarizado entre comportamento hedônico e utilitário de consumo, as preferências do consumidor, mesmo que ele seja um utilitarista, poderia não se apresentar absolutamente objetiva. Acredita-se que, dada a característica da atividade turística, sua conduta também estivesse voltada aos seus próprios estados subjetivos, implicando também na participação de orientações hedônicas no seu processo de decisão de compra por determinado alimento (HADDAD, 2003).

\section{CONCLUSÃO}

Alguns fatores relacionados à pesquisa fazem desse trabalho um dos pioneiros nesse tema, entretanto, a falta de dados seguros sobre o perfil da demanda turística da cidade de Campo Grande e sua distribuição ao longo dos anos, bem como a escassez de trabalhos que contemplem desenvolvimento de produto turístico relacionado à alimentação, criam certas limitações na caracterização estatística do comportamento alimentar dos turistas que visitam a cidade durante todo o período do ano.

Apesar de apresentar um percentual menor em relação ao comportamento utilitário no consumo de alimentos, o comportamento hedônico dos turistas mostra-se significativo em relação aos motivos que levam um turista a determinar a sua escolha 
alimentar. Isso demonstra a importante influência do contexto na escolha alimentar, o que nesse trabalho é apresentado como a visita a um destino turístico. Para que essa premissa fosse mais bem fundamentada seria necessária a realização de estudos com esses mesmos turistas em seus locais de residência para se constatar se o seu comportamento alimentar apresenta uma variância significativa.

As escolhas dos turistas por produtos como peixe e churrasco, por exemplo, confirma a associação que os visitantes poderiam fazer entre os alimentos e o perfil de Mato Grosso do Sul, além de associar também aspectos da imigração japonesa à cidade de Campo Grande, representados pelo sobá. Foi constatado que, orientados pelo comportamento hedônico de consumo, os visitantes puderam, a partir das mais diferentes motivações, elencar esses produtos como os principais relacionados aos aspectos lúdicos da cidade.

Assim como foi identificado que as mulheres apresentaram uma maior tendência para o hedonismo em relação aos homens, por exemplo, o mercado voltado para produtos típicos, que tem no hedonismo um importante aliado, poderia voltar parte da sua atenção para a conquista do público feminino ou, então, de um grupo mais amplo de turistas a partir da aproximação com esse gênero. Isso poderia otimizar os esforços publicitários para esses produtos.

Esse trabalho contribui para o desenvolvimento de produtos turísticos a partir da segmentação do mercado, pois, com a detecção do comportamento do turista em relação ao alimento, torna-se possível oferecer produtos e serviços adequados para cada tipo de turista que esteja presente em um determinado destino turístico.

\section{REFERÊNCIAS}

ANDRADE, J. V. Turismo: fundamentos e dimensões. São Paulo: Ed. Ática, 1998.

BABIN, B. J.; LEE, Y. K.; KIM, E. F.; GRIFFIM, M. Modeling consumer satisfaction and word-of-mouth: restaurant patronage in Korea. Journal of Services Marketing, 19 (3), p. 133-139, 2005.

BABIN, B. J.; DARDEN, W.; GRIFFIN, M. Work and/or fun: measuring hedonic and utilitarian shopping value. Journal of Consumer Research, 20, 1994. 
BATRA, R. Measuring the hedonic and utilitarian sources of consumer attitudes. Marketing Letter, 2 (2), 1991.

BECKER, T. Consumer perception of fresh meat quality: a framework for analysis. British Food Journal, 102 (3), p. 158-176, 2000.

CLARK, K.; WHEELWRIGHT, S. C. Managing new product and process development: text and cases. New York: Free Press, 1993.

DECI, E. L.; RYAN, R. M. Intrinsic motivation and self-determination in human behavior: perspectives in social psychology. New York: Plenun Press: 1985.

DENCKER, A. F. M. Métodos e técnicas de pesquisa em turismo. 5. ed. São Paulo: Futura, 2001.

GAINS, N. The repertory grid approach. In: MACFIE, H. J. H. Measurement of food preferences. Gaithersburg, Maryland: Aspen, 1999.

GLASER, B. G.; STRAUSS, A. L. The discovery of grounded theory: strategies for qualitative research. Chicago: Aldine Publishing Company, 1967.

HADDAD, F. Dialética positiva: de Mead a Habermas. Lua Nova, 59, 2003.

HJALAGER, A. M.; CORIGLIANO, M. A. Food for tourists - determinants of an image. International Journal of Tourism Research, v. 2, p. 281-293, 2000.

HOCHSCHILD, A. R. The managed heart: commercialization of human feeling. Berkeley: University of California Press: 1983.

IBGE. Instituto Brasileiro de Geografia e Estatística. Economia do turismo: uma perspectiva macroeconômica 2003-2006. Rio de Janeiro, RJ: IBGE, 2009

KARLSSON, C. Researching operations management. New York: Routledge, 2009.

KRIPPENDORF, J. Sociologia do turismo: para uma nova compreensão do lazer e das viagens. Rio de Janeiro: Ed. Civilização Brasileira S. A., 1989.

LAROUSSE CULTURAL. Dicionário de língua portuguesa. São Paulo: Nova Cultural, 1992.

MALHOTRA, N. Pesquisa de marketing: uma orientação aplicada. Porto Alegre: Bookman, 2006.

MASLOW, A. H. A theory of human motivation. Psychological Review, 50, 1953.

MINISTÉRIO DO TURISMO. Turismo no Brasil prevê crescimento de $20 \%$ no primeiro bimestre do ano. Recuperado em 15/09/2009, de http://www.turismo.gov.br/turismo/noticias/. 
MORALES, A. A. Tendencias en la producción de alimentos: alimentos funcionales. Revista Salud Pública y Nutrición, 3 (3), 2002.

MUROLO, A. C. Estatísticas para os cursos de administração, economia e ciências contábeis. São Paulo: Atlas, 1997.

OMT. Concepts, definitions et classifications pour les statistiques du tourisme. Mannuel Technique, OMT, 1994.

QUAN, S.; WANG, N. Towards a structural model of the tourist experience: an illustration from food experiences in tourism. Tourism Management, 25, 297-305, 2004.

REYNOLDS, P. Culinary heritage in the face of tourism. Progress in Tourism, Recreation and Hospitality Management, v. 6, p. 189-194, 1994.

ROZENFELD, H.; FORCELLINI, F.; AMARAL, D. C.; SILVA, S.; ALLIPRANDINI, D.; TOLEDO, J. C.; SCALICE, R. Gestão de desenvolvimento de produtos: uma referência para a melhoria do processo. São Paulo: Saraiva, 2006.

SIEGEL, S. Estatística não-paramétrica para as ciências do comportamento. Editora McGraw-Hill do Brasil, 1977.

TRISKA, L. N. S. Prazer e bem estar no ambiente de trabalho: a importância do olfato na ergonomia. Dissertação (Mestrado em Engenharia da Produção). Programa de Pós-Graduação em Engenharia da Produção. Universidade Federal de Santa Catarina, Florianópolis, SC, Brasil. 2003.

URRY, J. O olhar do turista: lazer e viagens nas sociedades contemporâneas. São Paulo, SP: Studio Nobel - SESC, 1999.

Recebido em: 18-01-2011.

Aprovado em: 18-02-2011. 